\title{
El temor y sus movimientos: políticas cómicas del phóbos en Ranas de Aristófanes

\author{
Fear and its Movements: \\ Comic Politics of Phóbos in Aristophanes's Frogs
}

\author{
EMILIANO BUIS \\ Universidad de Buenos Aires y CONICET \\ ebuis@derecho.uba.ar
}

Recibido: 2/08/2019 - Aceptado: 4/11/2019

DOI https://doi.org/10.20318/fons.2019.4911

\begin{abstract}
Resumen
Mucho se ha debatido en torno de la unidad argumental de la comedia Ranas de Aristófanes y del rol que, frente a las primeras escenas, juega en la trama el extenso agón formal entre Esquilo y Eurípides. En el marco de un proyecto mayor que procura estudiar las emociones (re)presentadas sobre la escena aristofánica, este trabajo pretende explorar las alusiones cómicas al temor como elemento afectivo clave para echar luz sobre la consistencia dramática de la obra. Postulamos que, si en la primera parte de la comedia se opone -en un personaje como Dionisoel coraje pretendido y el temor real, en los versos corales de la segunda parte se consagra una arenga que, en términos de combate, responde a una intención de imponer orden y canalizar las emociones para superar el miedo. Así, frente al miedo privado y apolítico que al comienzo de la obra produce risa al inmovilizar y privar a Dioniso de su condición ciudadana, se consagra finalmente un phóbos político capaz de movilizar e instruir a la pólis.
\end{abstract}

Palabras clave: miedo, Aristófanes, Ranas, Dioniso, emociones, política

\section{Abstract}

This paper aims to explore the comic allusions to fear as a passion that can shed light on the underlying dramatic coherence. In the first half of the comedy, Dionysus's declared courage opposes his real fear, but the choral verses of the second part endorse a military harangue that intends to impose order and administer emotions to overcome fear. Against the private and apolitical fear which produces laughter at the beginning by immobilizing and depriving Dionysus of his citizenship, the play finally enshrines political phobos to mobilize and instruct the polis.

Keywords: fear, Aristophanes, Frogs, Dionysus, emotions, politics

\section{Introducción ${ }^{1}$}

Un grupo de batracios, primero; un conjunto de iniciados, después. No es común que en una obra aristofánica aparezcan sucesivamente dos coros diferentes e

${ }^{1}$ El presente trabajo se enmarca en una investigación más amplia que, como parte de un plan de trabajo en el CONICET y de un proyecto grupal UBACyT, procura analizar el rol político de las emociones en la comediografía griega. 
independientes. A partir de esta constatación y de otras alegadas inconsistencias que aparecen a lo largo de los versos, mucho se ha debatido en torno de la unidad argumental de la comedia Ranas de Aristófanes y del rol que, en la trama, termina jugando el extenso agón formal entre Esquilo y Eurípides en el que se discute quién es el mejor tragediógrafo ateniense (vv. 830-1532) ${ }^{2}$. En el marco de un proyecto mayor que procura estudiar las emociones (re)presentadas sobre la escena aristofánica, el presente trabajo propone una lectura interesada en retomar algunas alusiones cómicas en Ranas al plano afectivo. En esta clave, pretendemos aquí explorar las numerosas (aunque escasamente estudiadas) referencias humorísticas al temor como elemento subjetivo fundamental para comprender, al menos en cierto grado, una posible unidad subyacente en la composición de la obra vinculada con la contraposición entre el plano individual del miedo y su dimensión política (en su faceta bélica y dramática). Mediante una antítesis entre la pasividad y la acción, la cobardía y el individualismo de Dioniso, que se vislumbran en la primera parte, dejarán lugar luego a la consagración de una valentía que responde a los valores colectivos que promueven tanto el coraje militar como el arrojo poético.

\section{El miedo, entre Trump y Aristóteles}

El miedo es claramente una emoción determinada por la experiencia subjetiva, en la medida en que constituye la anticipación percibida de un dolor bien identificado que se vincula además con la pretensión de evitar ese sufrimiento todavía no consumado ${ }^{3}$. Detrás de la idea del temor se halla un constructo imaginado, una percepción ficticia de lo que podrá ocurrir (la idea de un peligro susceptible de traducirse en una fuerza en el futuro) o de lo que se recuerda que ocurrió (una rememoración de un dolor pasado que podría reiterarse) $)^{4}$.

\footnotetext{
${ }^{2}$ Así, por ejemplo, se expresa Russo 1994, 205, al sostener que «the two sections of Frogs, therefore, deal with completely different subjects, are governed by different performance- and stage-techniques and involve two distinct sets of characters (with the exception of Dionysos, who in the first part, none the less, almost always keeps his identity concealed)». Seguimos a este autor a la hora de distinguir, como también hacen otros, dos "partes" bien diferenciadas en la pieza.

${ }^{3}$ En este trabajo utilizaremos las palabras castellanas "miedo" y "temor" como sinónimos, a pesar de que sería posible discutir algunas diferencias sutiles entre sus alcances semánticos. Ambos términos se distinguen de la "angustia" que, según la psicología, es una espera dolorosa ante un peligro que no se logra identificar claramente. Véase DELuMEAU 2002, 10. Acerca de la pluralidad terminológica en inglés, HOLLANDER 2004 señala que las palabras que se emplean están influenciadas por una serie de variables vinculadas con la gravedad del evento que produce la emoción, la presencia de gente, la edad y el status social del agente, la posibilidad de huir, entre otros elementos contextuales.

${ }^{4}$ Cf. DE COUR VILLE NICOL 2011, 16, quien añade: «The threat posed by a force is always imagined, since a force cannot be said to be dangerous in and of itself, or to contain danger». HeLLER 1999 [1979], 102-103, distingue la "emoción" del miedo (cuando se dirige al futuro o al pasado) y el "afecto" del miedo, motivado por un estímulo basado en la experiencia personal o en un saber social adquirido respecto de la peligrosidad de ese objeto. Aquí no haremos esta distinción, considerando que ambas experiencias emotivas son interdependientes.
} 
$\mathrm{Al}$ referirse a la vez a una anticipación y a una recreación, el miedo deviene entonces configurado por la representación de que algo ocasionará un dolor ${ }^{5}$. Esta sensación de desamparo que está involucrada en el miedo lo convierte en una emoción profundamente individual, en la medida en que la recuperación mental del riesgo y de las consecuencias de una fuerza conceptualizada como amenazante resulta un ejercicio que resulta diferente en cada individuo ${ }^{6}$. Recientemente, en un libro que despertó cierta polémica entre los filósofos y politólogos estadounidenses, Martha Nussbaum se ha ocupado de analizar los riesgos de la democracia norteamericana bajo la presidencia de Donald Trump desde una mirada que se focaliza en el rol central del miedo7. Según ella, el miedo es por su propia naturaleza a-social y narcisista, en tanto surge y se agota en la propia persona que lo siente. En este sentido, corroe las bases de la reciprocidad democrática en tanto quiebra el equilibrio de la comunidad a partir del aislamiento y la atomización y promueve un enojo retributivo que resulta profundamente divisivo. La construcción retórica del miedo -pues el temor es una de las emociones más permeables a la manipulación argumentativa- es lo que, según Nussbaum, explica la crisis de legitimación del gobierno actual de los Estados Unidos, que encuentra en gran medida su autoridad en la producción de miedo para inmovilizar e impedir reacciones. En efecto, además de ser individual, el miedo posee un efecto paralizante en la persona que lo experimenta: lleva al detenimiento, a una suspensión del razonamiento o de la percepción del ambiente que rodea a esa persona, quien termina entonces encerrada en sí misma ante la virtualidad del efecto nocivo ${ }^{8}$.

Como suele ocurrir en sus obras, Nussbaum construye su marco conceptual a partir de raíces teóricas que la remontan a los pensadores griegos y romanos. Dicha remisión es relevante en tanto nos permite reexaminar los riesgos políticos implicados en la manipulación de las emociones por parte de los oradores de época clásica. Respecto del mundo helénico, cuando Chantraine explica las bases etimológicas de los términos empleados para indicar el miedo, distingue el término фóßos (temor que invade a alguien y lo impulsa a huir) de $\delta$ źos, que implica más bien una aprehensión,

${ }^{5}$ Ese algo que tememos puede ser un evento, objetos reales o ficticios, o incluso abstracciones (STARKSTEIN 2018, 1). De acuerdo con TAPPOLET 2010, 328-329, para que produzca miedo ese algo debe ser construido como temible por parte del agente.

${ }^{6}$ Para un estudio clínico respecto de los síndromes derivados del miedo, así como de los mecanismos que lo producen, ver MARKS 1987, donde además puede consultarse una amplísima bibliografía sobre el tema. GRAY 1987 (1971), 27 sostiene que la expresión del miedo constituye una respuesta a un factor o comportamiento temible (fearful behavior), que puede consistir en un enojo, una agresión, una amenaza certera o una dominación. Acerca de los distintos tipos de miedo (miedo a algo, miedo de hacer algo, miedo de que suceda algo, o simplemente miedo en sí mismo) puede consultarse DAVIES 1987.

${ }^{7}$ Nussbaum 2018.

8 «Having such strong emotions, which implies stopping moving, perceiving, reasoning or even forming images for a moment, is quite a common experience. Emotion arrives on the scene putting suddenly a stop to the acting of those faculties through which the organism normally explores the environment, analyses circumstances, processes and combines information. In cases which could be devastating like being paralysed with fear, it turns out that the drive towards outside, which characterises even the simplest organism, suffers a kind of recoil and turns on itself» (FUSELLI 2018, 106). 
un temor reflexivo que se vincula con la inquietud de quien se ve ante un dilema9. Si bien reconoce que en las fuentes estos dos vocablos pueden ser empleados como sinónimos, y de hecho en algunos autores lo son ${ }^{10}$, no deja de ser llamativo que detrás del фóßos pareciera existir la idea de un miedo que impacta y lleva a la huida,

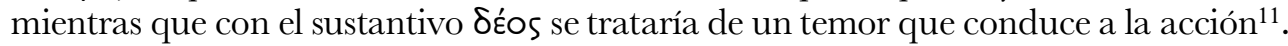

Los testimonios antiguos no parecen ser tan tajantes como pareciera dar a entender esta distinción léxica. Al momento de definir el temor (phóbos) -ubicado dentro del listado de diez páthe que nos of rece en el libro II de su Retórica- Aristóteles indica que "es una clase de dolor o molestia que se deriva de la impresión de un mal futuro que

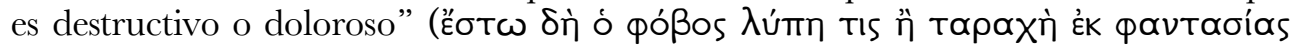

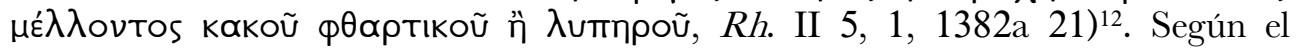
estagirita, este temor necesita ser próximo, dado que no se temen aquellas cosas que son remotas, como señalamos al comienzo. También para Aristóteles se trata en efecto de identificar una circunstancia de peligro capaz de despertar nuestra reacción frente a la eventual producción de un dolor ${ }^{13}$. A pesar entonces de que se trataba allí igualmente de una emoción del orden de lo individual ${ }^{14}$, en tanto surge de la configuración de ese mal inminente, pareciera que en la reflexión aristotélica el phóbos no desemboca en una inmovilización.

En efecto, a diferencia del pánico ('̌k $\pi \lambda \eta \xi 15)$, que es un shock que paraliza ${ }^{15}$, el phóbos, que como vimos se sustenta en inferencias a partir de una evaluación de lo que puede ocurrir, parece generar la posibilidad de una toma de decisiones en el fuero íntimo ${ }^{16}$. El propio Aristóteles dirá, pues, que el miedo nos hace a cada uno

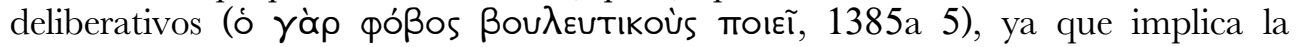
respuesta condicionada a una imagen mental que comprende que algo es una amenaza y actúa o responde en consecuencia. Si el miedo debe estar acompañado de una expectativa de que algún acontecimiento destructivo puede aparecer, resulta claro que depende de lo que alguien piense o crea de sí mismo -sus propias vulnerabilidades y fortalezas- y de lo que lo rodea (1382b 29-1383a 3). El phóbos se presenta entonces como algo ambivalente en las fuentes antiguas: evidentemente siempre es reactivo, y sin embargo los modos mediante los cuales se procesa esa

\footnotetext{
${ }^{9}$ Chantraine 1999 [1968], 1184.

${ }^{10}$ Hâncu 2016, 16.

11 Todos estos términos ya se hallan presente en la épica homérica. En un trabajo exhaustivo,

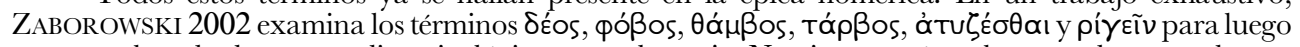
compararlos, desde un estudio psicológico, con el coraje. Nos interesará en la segunda parte de este artículo explorar esa vinculación entre temor bélico y valentía.

${ }^{12} \mathrm{El}$ texto griego corresponde a la edición de Ross 1959. Las traducciones, aquí y en el resto del trabajo, nos pertenecen en todos los casos.

${ }^{13}$ Este sentido del "miedo" coincide con una de las modalidades que planteará Diógenes de Enoanda en el seno de la escuela epicureísta; cf. KONSTAN 2008, 48.

${ }^{14} \mathrm{El}$ temor presupone un alto grado de egoísmo y, al ser una emoción "self-focused”, suele darse en contextos no políticos; cf. LaCourse MunTEANu 2012, 16 y 19.

${ }_{15}$ NAGY 2010, 31.

${ }^{16}$ KONSTAN 2006, 130: «Fear involves knowledge and inference».
} 
respuesta emotiva (es decir, aquello que le sigue a la experiencia del temor) puede variar según el contexto y de acuerdo con cada persona.

En tanto se trata de uno de los modos en que es factible canalizar ese impacto, en la teorización aristotélica existe una fuerte asociación de este miedo con el coraje. De hecho, quien manifiesta valentía sabe tener miedo por las razones correctas, y eso es lo que lo motiva a actuar. En Ética a Nicómaco (1116b 17-19), texto que complementa la visión proporcionada en Retórica en la medida en que consagra una lista de virtudes morales asociadas con las emociones, esta analogía deviene incluso más clara:

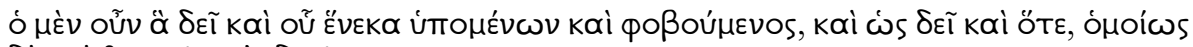

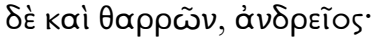

Quien soporta y teme las cosas que es necesario [soportar y temer] a causa de la buena razón, como y cuando es necesario [soportar y temer], y del mismo modo al ser temerario, es un valiente.

Puede decirse que la andreía o coraje se encuentra en un justo medio entre dos extremos que deben ser rehuidos: el atrevimiento (1115a 7, thársos), que es defectuoso por exceso, y el miedo (phóbos), que resulta entonces negativo por deficiencia ${ }^{17}$. Entre quien confía en sí mismo de manera tan irreflexiva ( $\theta$ paoús, 1115b 29) que va más allá de lo prudente, y el cobarde ( $\delta \varepsilon ı \lambda o ́ s, 1115 b 34)$ que resulta preso del miedo también de modo irrazonable, debe hallarse un punto de equilibrio, dado por las razones adecuadas (el ejercicio correcto del lógos) ${ }^{18}$ que un ciudadano ha de tener para temer. El coraje, pues, es una virtud de acción que regula la emoción del miedo ${ }^{19}$. Aquí aparece, en nuestra opinión, la importancia política del nivel adecuado de temor, que lleva a pensar en una proyección del miedo individual al plano más colectivo de la vida en común en la pólis. La virilidad esperable en todo buen polites, pues, consiste en enfrentar de manera racional las situaciones de mal inminente sin escaparse de ellas o quedar inactivo; atacar con juicio el buen temor, rehuir del pánico o del terror para enfrentar las amenazas cercanas. Deviene evidente el carácter cívico involucrado en el correcto grado de temor, en la medida en que funciona como un alerta respecto de posibles males sobrevinientes ${ }^{20}$.

Controlar el phóbos para que sirva de motor de decisión es una tarea adecuada para el ciudadano imbuido en un sentimiento de valentía. Reponer estos alcances políticos del miedo deviene útil cuando se analiza la escena aristofánica -

17 BONANNO-CORSO 2018, 238.

${ }^{18}$ FORTENBAUGH $2002^{2}, 103$.

19 KRISTJÁNSSON 2007, 18.

${ }^{20}$ En la actualidad, BISQUERRA 2017, 45, ha sostenido al analizar el vínculo entre el sustrato emotivo y la política que, mientras el miedo es una emoción, la cobardía es un comportamiento, agregando: «La valentía no significa no tener miedo, sino superarlo conscientemente para afrontar retos y peligros que merecen la pena [...]. Afrontar el peligro y ponerse en riesgo sin necesidad no es valentía, sino imprudencia o temeridad». 
especialmente Ranas-, en tanto allí se presenta una praxis vinculada con esta discusión que jugará de manera humorística con los diferentes niveles semánticos comprendidos bajo las modalidades variadas del temor, sus efectos (la parálisis o la acción), sus reacciones (individuales o colectivas) y sus nexos con los valores de la prudencia, la valentía o la cobardía.

\section{Dioniso en Ranas: miedo, reacción privada e inmovilidad}

En la primera parte de Ranas, representada en las Leneas del 405 a.C., el phóbos parece estar focalizado en la figura de Dioniso. Esta caracterización del dios en clave emotiva es relevante en la medida en que, como protagonista cómico, está fuertemente connotado por un notorio individualismo ${ }^{21}$. Este aislamiento, que no es extraño pues caracteriza a la mayor parte de los héroes aristofánicos, es central para comprender la circulación emotiva de las primeras escenas de la pieza. Así, cuando al comienzo el protagonista se vanagloria frente a su esclavo Jantias de ser capaz de asustar cuando golpea la puerta de Heracles, Dioniso se describe a sí mismo como

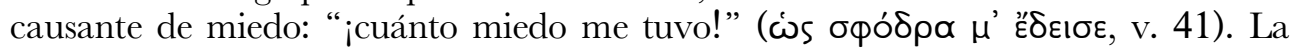
construcción personal que la divinidad hace de sí misma en términos discursivos frente a su interlocutor (y frente al auditorio) da cuenta de una soberbia y autoconfianza que contrastarán pronto con sus actitudes no discursivas. Cuando en el avance de la trama decida dirigirse al inframundo, ese espacio que alegaba ocupar como causante de miedo se desarticulará ante los ojos de los espectadores. En el trayecto físico que se produce desde Atenas al Hades -desde la vida a la muerte-, es factible advertir en Dioniso un recorrido metafórico paralelo que lo lleva de su auto-reconocida superioridad inicial a una progresiva demostración de su real condición cobarde. En este traslado de la palabra a los hechos, a medida que desciende hacia los infiernos, la configuración del personaje de Dioniso experimenta un derrotero que lo va llevando, cómicamente, hacia lo más profundo de su mediocridad mediante la explotación de un temor personal e intimidante.

Así, en cuanto Heracles le describe el descenso al Hades, donde habrá una gran laguna que deberá atravesar para luego hallar serpientes y mil criaturas feroces, Dioniso recurre una vez más a su pretendido valor, caracterizado ahora a partir de un rechazo del temor: "No me espantes ni me des miedo, no me vas a hacer dar

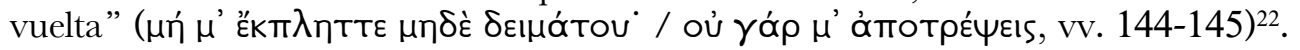
$\mathrm{El}$ discurso traduce desde la individualidad una aparente valentía que lo lleva a rechazar la disuasión. En sus palabras, Dioniso no teme porque -como buen personaje cómico y a diferencia de lo que puede imaginar la audiencia respecto de lo que

\footnotetext{
${ }^{21}$ De hecho, esta es una de las características esenciales del "héroe" cómico, que a pesar de lo bueno que puede surgir de sus actos, nunca deja de estar motivado por un «powerful, self-centered individualism» (WHITMAN 1964, 26).

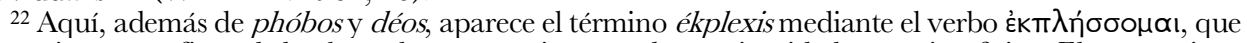
como vimos se refiere al shock o a la sorpresa inesperada que impide la reacción física. El texto griego para las citas de Ranas corresponde a DOVER 1993, pero se han tenido también en cuenta para el contraste las otras ediciones consignadas en la bibliografía.
} 
ocurrirá- no advierte la inminencia de ningún mal eventual. Sin embargo, como se advertirá enseguida, el público habrá estado en lo cierto y el panorama tétrico de la vida en el Hades lo llevará pronto a una realidad muy distinta en la que experimentará la emoción del miedo en carne propia. Cuando efectivamente realice la katábasis, se instala un juego de comicidad fundado en la exageración: al ver a Empusa (v. 293) el monstruo con el rostro en llamas-, Dioniso intentará huir y buscar protección con su sacerdote, sentado en la primera fila del teatro (v. 295)23. Enseguida reconocerá

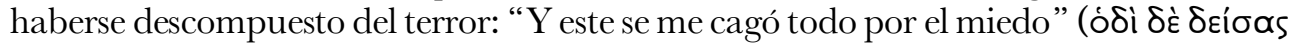

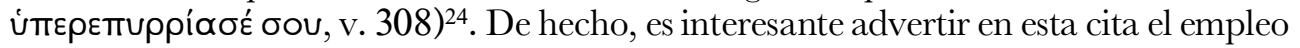
de una tercera persona, "este" (ódi), atribuyendo el accionar escatológico a una parte de su cuerpo y no a su propia individualidad. El proceso de inmovilización es evidente, en tanto la subjetividad de Dioniso queda así apartada por la agencia de su propio cuerpo, como si se tratara de atribuir la responsabilidad del hecho a otro ${ }^{25}$.

El contraste cómico entre los dichos iniciales y los hechos actuales no puede ser más notorio. Los planos espacial, somático y lingüístico se superponen alinéandose ahora en las antípodas de lo que se expresó en un comienzo. Si antes el olímpico Dioniso se presentaba como un dios capaz de sobreponerse al miedo con un lenguaje elevado, ahora el descenso material al Hades encuentra eco tanto en una bajada corporal como en la caída del registro: el ambiente externo se corporiza en un sufrimiento intestino ${ }^{26}$. La inversión también se ilustra en el vocabulario: el verbo deídomai, que según Chantraine referiría a un temor que genera conciencia, en verdad aquí traduce un pánico inmovilizador.

De lo alto del Olimpo a lo bajo del Hades, de lo alto de las palabras a lo bajo de los flujos del cuerpo. En términos de presentación del propio Dioniso, la caída es estrepitosa y da cuenta de que sus aparentes fortalezas, evocadas en sus primeras intervenciones al referirse no sólo a que no sentía miedo sino a que él mismo provocaba ese miedo en los demás, ocultaban verdaderas debilidades. Quien afirma insistentemente no tener miedo y termina liberando sus esfínteres sobre el escenario deja entrever una alta dosis de humorismo y resulta eficaz para la puesta en escena de toda la primera parte de la pieza ${ }^{27}$.

${ }^{23}$ Csapo 2010, 130. Acerca del lugar privilegiado en el que se sentaba este sacerdote en el teatro, cf. Rogers 1968, 324. Esta referencia muestra que el temor aparece ligado al rol dramático de Dioniso y no, como ocurrirá en la segunda parte de la obra, a una dimensión cívico-política.

${ }^{24}$ Según Frenkel et al. 2011, 127, n. 47, el motivo del descontrol de esfínteres es habitual en Aristófanes, como se vislumbra en otras obras: Au. 65 ss., Nu. 293 ss., V. 626 ss., Ec. 1059 ss., Pl. 693.

${ }_{25}$ SomMERSTEIN 1996, 182, reconoce que el sujeto de la acción es un objeto masculino diferente del hablante, y sugiere que se trata o bien de su ano o de su vestido azafranado. En el mismo sentido se había expresado ya DOVER 1993, 231.

${ }^{26}$ BLIQUEZ 2008 señala que aquí hay un juego léxico con los vv. 152-153, en los que se menciona a Cinesias, quien se supone debió de haber tenido algún célebre episodio de diarrea al que se hace alusión con la referencia al cólor “pírrico”. Cf. KIDD 2014,92. Acerca de las representaciones cómicas del cuerpo en estas escenas y sus alcances liminares en términos rituales, cf. LADA-RICHARDS 1999, 117-118.

${ }^{27}$ No es el único caso en el que el miedo se asocia sobre la escena aristofánica con la defecación: además del pasaje 479-497, que analizaremos a continuación, puede mencionarse $E q$. 1057, Pax 241 y 1176. 
Dioniso inicia el descenso al Hades disfrazado de Heracles y, sin embargo, si al principio ambos roles se ven superpuestos, la simetría prontamente se desarticula. Heracles es descripto como sujeto activo del temor cuando una de las hospederas, Platane, alega haber tenido miedo de él cuando les robó su albergue ( $\delta \varepsilon ı \sigma o ́ \sigma \alpha, 565)$. Dioniso, en cambio, sucumbe pasivamente ante la debilidad de su vientre cuando lo asustan las amenazas de Éaco (vv. 479-485):

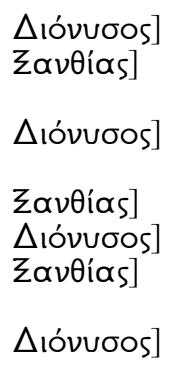

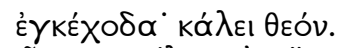

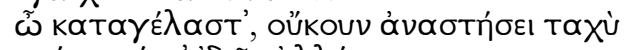

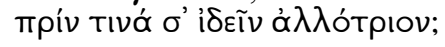

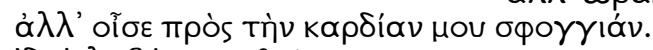

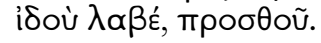

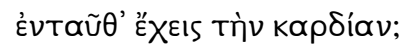
пой 'oTIV; ๘̃ Xрบఠоі̃ $\theta \varepsilon \circ i$,

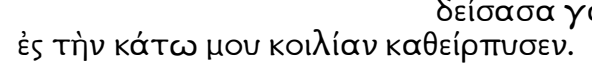

Dioniso: Me he cagado. Llama al dios. Jantias: ¡Oh, ridículo! ¿No te vas a levantar rápido antes de que otro te vea? Dioniso: Me desmayo. Tráeme una esponja para el corazón. Jantias: Aquí tienes, póntela. Dioniso: ¿Dónde está? Jantias: ¡Oh, dioses dorados! ¿Ahí tienes el corazón? Dioniso: Es que, por tener miedo, se me fue abajo para el vientre.

Como hemos mencionado, el descenso del corazón a las tripas traduce, en un registro corporal, las consecuencias del viaje "hacia abajo". El desmayo contribuye a mostrar la inmovilidad y la falta de control de la divinidad sobre el estado de su cuerpo. Una vez más, la acción del temor bloquea a Dioniso, quien en este caso de nuevo borrará su subjetividad al atribuir el miedo a una tercera persona sintáctica: en

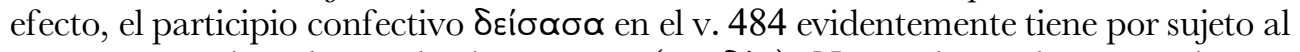

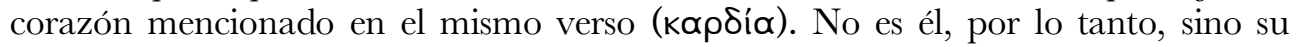
corazón el que está aterrado.

Por lo demás, en este mundo del revés, en que los personajes se invierten, aparece una transformación en la que se revela la cobardía de Dioniso (vv. 486-497) y su intento verbal por demostrar que, al ponerse de pie (es decir, al moverse hacia arriba) es más valiente que los que permanecen abajo, recostados por el espanto:

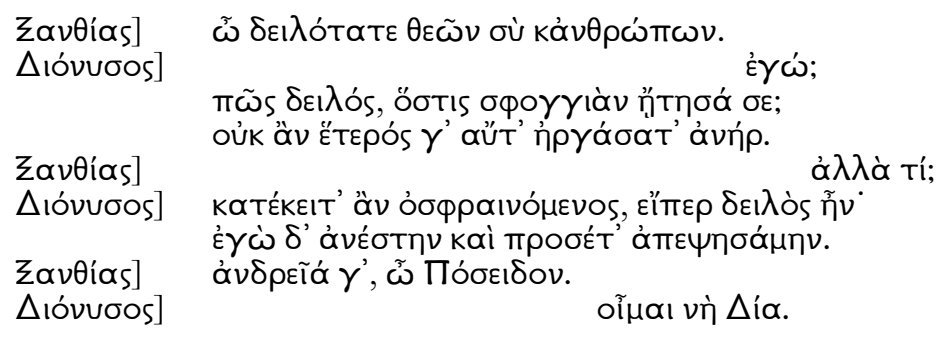

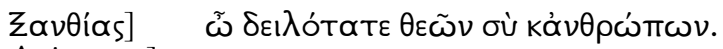

$\triangle$ Ióvvoos]

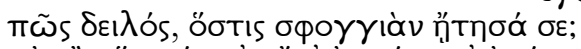

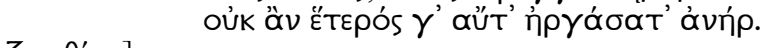

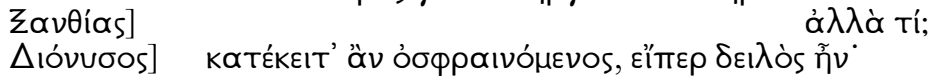

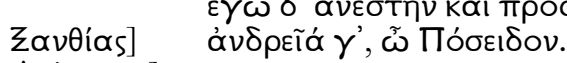

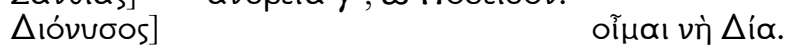


Zav日ías] $\triangle$ ióvvoos]

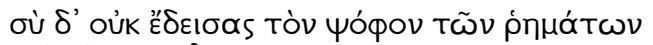

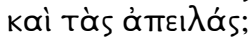

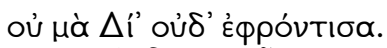

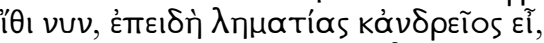

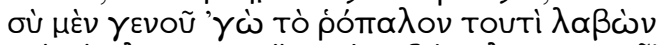

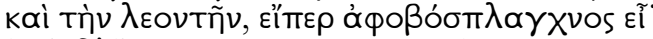

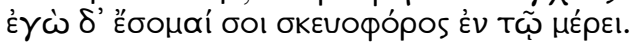

Jantias: ¡Oh, el más cobarde de los dioses y de los hombres! Dioniso: ¿Yo? ¿Cómo cobarde, porque te pedí una esponja? Otro hombre no habría hecho esto. Jantias: ¿Sino qué? Dioniso: Se recostaría olfateándola, si fuera cobarde; en cambio yo me levanté y me lavé. Jantias: ¡Pero qué valentía, por Poseidón! Dioniso: ¡Ay, por Zeus! ¿Y tú no tuviste miedo del sonido de las palabras y de las amenazas? Jantias: No, por Zeus, ni me inquieté. Dioniso: Ve, entonces, ya que eres un corajudo y valiente, jtransfórmate en mí con ese garrote y la piel de león, si eres un vientre sin miedo! Yo, en cambio, voy a ser, a mi turno, tu cargador de bártulos.

El intercambio dialógico se sostiene en un debate sobre la andreía de ambos personajes ${ }^{28}$. A partir de la contraposición entre un aparente coraje y una demostrada cobardía, la reacción de Dioniso lleva a que los personajes terminen intercambiando sus ropas y sus roles: el dios cederá su vestimenta de Heracles a Jantias y pasará a comportarse él mismo como esclavo: en la transformación, será Jantias el agente que

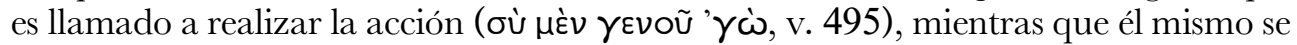
coloca en la posición de un hombre objeto: será simplemente quien transporte el equipaje (бKEvoфópos, v. 497). Dioniso prefiere entonces comportarse en un rol servil que ser sometido a esas fuerzas que lo asustan. En términos cómicos, el miedo individual entonces lleva a una pérdida de identidad en la que el amo pasa a estar sometido, en la que no hay espacio para la ciudadanía ${ }^{29}$.

Como un doûlos, Dioniso será torturado sobre el escenario (v. 626 ss.), y en esa victimización se transforma en un mero cuerpo sometido a la violencia. Desarticulado su lógos, deja ser un polítes capaz de dominar a sus esclavos y pasa a no poder controlar sus intestinos ni preservar la integridad de su cuerpo, el cual resultará atado para ser sometido a una básanos cómica ${ }^{30}$. El miedo, que aquí lleva a la inmovilización más absoluta, presenta una capacidad transformadora muy adecuada para el efecto burlesco que procura la comedia. Pero la obra mostrará, en su segunda parte, cómo el temor se verá transformado para contraponer al miedo de Dioniso la reacción frente a un phóbos colectivo con una clara intencionalidad didáctica.

${ }^{28}$ BASSI 2003, 44-46.

${ }^{29}$ Demont 2007, 184, sostiene, analizando esta obra, que en la Atenas contemporánea el creciente poder de los esclavos era visto como una amenaza para los ciudadanos, que entonces sentían temor frente al fenómeno.

30 Acerca de esta escena de la básanos, cf. BuIs 2008, donde hemos mostrado que la anulación de la capacidad de acción ciudadana de Dioniso tiene como contrapartida la subjetividad cómica inusitada que se le otorga a un esclavo como Jantias, quien disfruta aquí por primera vez de ver a su amo tratado servilmente. 


\section{El coro-ejército en Ranas: miedo, acción colectiva y ascenso político}

La segunda parte de la obra, centrada en torno del certamen poético entre los tragediógrafos Esquilo y Eurípides, instala una nueva dimensión también ligada al plano afectivo del temor, pero ahora alejada de la des-subjetivación, la parálisis y la falsa valentía experimentadas por Dioniso. En este caso, las alusiones al miedo están más bien fundadas en la superposición de un phóbos propio del ámbito militar y otro relacionado con los riesgos de la propia puesta en escena ${ }^{31}$. Así, durante la oda el coro avanzará para instar a una danza de discursos, casi guerrera, que se edifica desde lo retórico como una verdadera arenga militar (vv. 895-904):

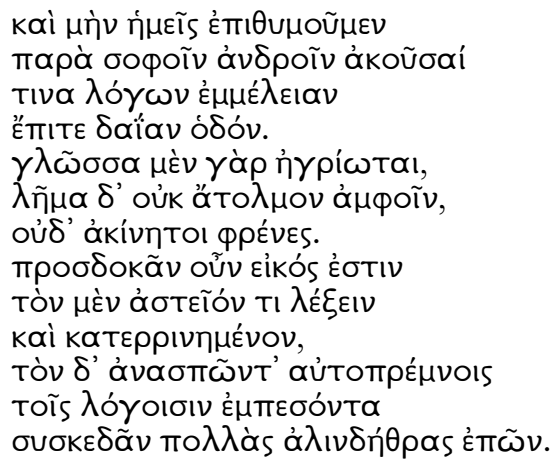

Y nosotros deseamos escuchar de los dos sabios una danza de palabras; sigan un camino destructor. Pues, por un lado, la lengua se ha vuelto salvaje; por el otro para ambos el coraje no está desprovisto de audacia ni los pensamientos están desprovistos de movimiento. Es ciertamente conveniente que uno diga algo elegante y pulido y que el otro, arrancando de raíz las expresiones, después de caer sobre ellas, disipe muchos revuelcos de discursos.

El cruce entre el discurso y la agresión física (danza de palabras, expresiones arrancadas, desplazamientos de términos), determinado en el contexto del agón, presentan la virtud del coraje como expresión de la audacia $(\lambda \tilde{n} \mu \alpha$ óto $\lambda \mu \circ v)$ y la dinamicidad de un enfrentamiento activo. El coro presenta entonces la instalación de un orden, capaz de mediar la violencia y, como se verá más adelante, de canalizar los

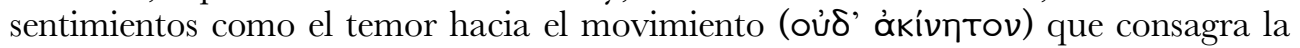
valentía y no hacia la inacción del pánico. En el antikatakeleusmós, el corifeo se dirige a Esquilo (vv. 1004-1005):

\footnotetext{
${ }^{31}$ No debe sorprendernos estos vínculos entre la performance bélica y la puesta en escena de las obras dramáticas. A partir de un respeto escrupuloso por la estructura formal, la actividad del ejército se aproxima a la de los coros teatrales, en tanto se trata de un colectivo unificado que actúa al unísono, con indicaciones muy claras del strategós / didáskalos. La guerra y el teatro, al igual que la asamblea o las cortes, constituían en la Atenas clásica espectáculos rituales de orden cívico, en el que la ciudadanía se representaba, afianzaba y definía. Estas semejanzas se refuerzan en las ocasiones como las que examinaremos a continuación, en las que los coreutas presentan de modo explícito alusiones a la virtud del combate. Cf. Buis 2018, 142-145.
} 


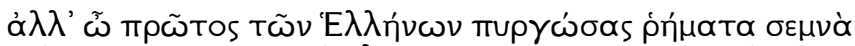

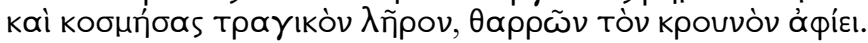

Pero tú, el primero entre los griegos que construiste las palabras venerables como torres y que adornaste el habla trágica, atreviéndote suelta el chorro.

Las analogías entre la arquitectura bélica (las torres) y la construcción de las palabras, como se advierte, se vinculan con el atrevimiento ( $\theta \alpha \rho \rho \tilde{v} v)$, que precisamente el propio Aristóteles contrapondrá al miedo desenfrenado e inmovilizante. De nuevo se consolida una acción positiva, en este supuesto ligada al verbo aphíemi ("soltar"), que ahora tiene por objeto una corriente o surtidor de agua (krounós). Al vincularse aquí metafóricamente la valentía de Esquilo con la subjetividad involucrada en el control de un manantial, las diferencias con el episodio ya visto de la diarrea de Dioniso, ocasionada por el pánico y fuera de su dominio (vv. 308 y 485), son considerables. Se trata de dos modalidades de agencia completamente opuestas respecto del manejo del flujo "líquido", que bien representan dos maneras de manipular la circulación de emociones ${ }^{32}$.

Algo semejante ocurrirá en la sphragís coral, cuando en los versos 1099-1108 se alienta a Esquilo y a Eurípides y se les pide que no teman, pues los espectadores son sabios:

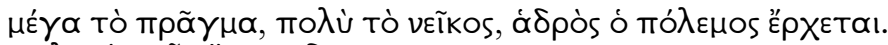

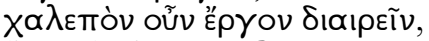

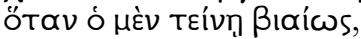

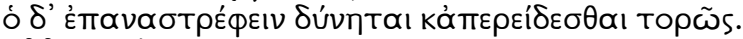

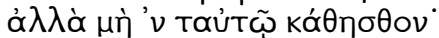

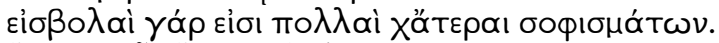

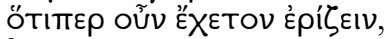

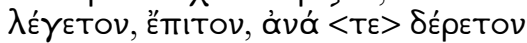

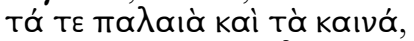

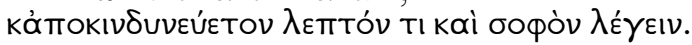

Grande es el asunto, mucha la pelea, la guerra avanza pesada. Ciertamente es tarea difícil distinguir cuando uno se extienda con violencia y el otro pueda darse vuelta y resistir con fuerza. Pero no os sentéis en el mismo lugar, pues son muchas y variadas las incursiones de los sofismas. Lo que precisamente tenéis vosotros dos para disputar, decidlo, atacad, liberad hacia arriba las cosas viejas y nuevas y corred el peligro de decir algo sutil y sabio.

${ }^{32}$ En un trabajo reciente sobre Gorgias y el empleo de las emociones, hemos propuesto la expresión "flujos afectivos" para caracterizar las operaciones por las cuales se emplea un juego retórico con las emociones dosificando su intensidad para conseguir efectos determinados en el interlocutor, como si se tratara de un chorro de agua cuyo volumen y caudal se regula de acuerdo con las circunstancias y el contexto. Cf. Buis 2020. 
El vocabulario de la pelea es constante en los sustantivos empleados (veĩoos,

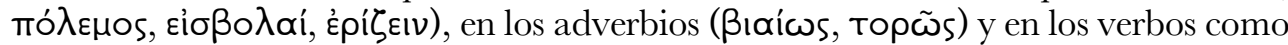
हैंTITOV, que en imperativo y en dual apunta a una arenga que se dirige hacia los dos adversarios de un agón bélico. Interesantemente, junto a este léxico castrense se introducen aquellos términos referidos a la controversia literaria que encuentra sostén

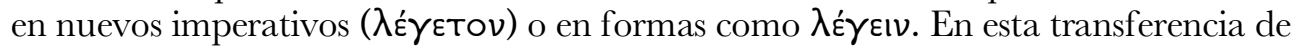
sentidos entre dos campos tradicionalmente diferentes se genera un movimiento que condice con la acción dinámica que el coro propone. El no quedarse sentado en el lugar se opone al ejercicio físico de extenderse, darse vueltas, resistir, liberar hacia arriba. Se trata de una invitación al desplazamiento que resulta contraria a la estaticidad y a la inmovilidad de la que había sido presa Dioniso en la primera parte de la obra.

Como quedará claro a continuación, se trata de instar un buen miedo, capaz de llevar a la acción, de movilizar desde la valentía. El riesgo (como se deja entrever en

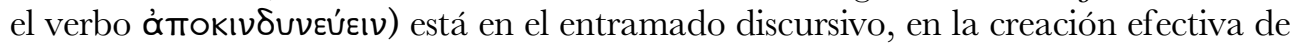
la sutileza literaria, lo que se relaciona con la sabiduría. Los mismos tejidos semánticos se reconocen en la segunda parte de la sphragís (vv. 1109-1118), en que el coro hace explícita una nueva alusión al miedo:

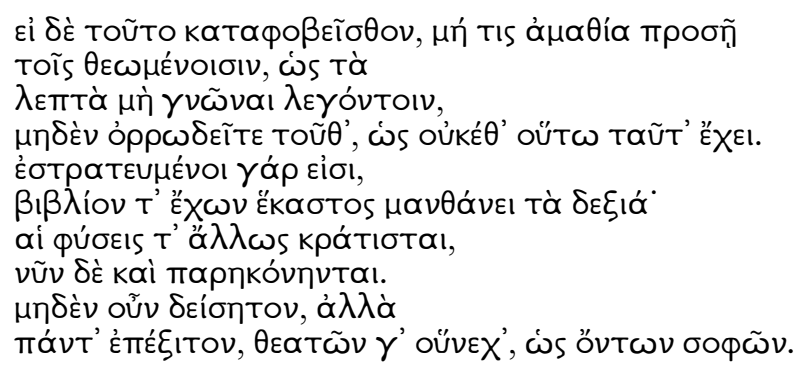

Pero si los dos tenéis miedo de esto, de que la falta de conocimiento se adose a los espectadores de modo que no sepan las cosas sutiles de las que hablan, no temáis esto, porque estas cosas ya no son así. Pues han ido a combatir y cada uno con su libreto aprende las cosas diestras. Y sus naturalezas por lo demás se imponen y ahora además están estimuladas. No temáis nada, enfrentad en cambio todo, por los espectadores, dado que son sabios.

En una superposición de nuevo entre el combate y la disputa literaria, se trata aquí de apartar el miedo (en el v. 1109 y luego, con una variación verbal, en el 1117) de una recepción no diestra de sus postulados. La falta de temor se vincula con la

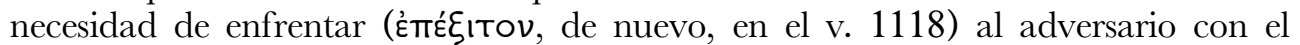
convencimiento de que el público sabrá comprender. En esta supresión del miedo para conseguir de modo eficaz el apoyo popular, confiando en la sabiduría de los espectadores, se traduce un accionar físico que es a su vez un movimiento de las palabras. 
Todo está ya listo para que, después del enfrentamiento poético, el traslado físico real que la obra postulaba desde el mundo de los mortales hacia el Hades se vea contrapuesto ahora por un desplazamiento ascendente que la segunda parte de la pieza consagra con la recuperación y la vuelta a Atenas del mejor tragediógrafo. El miedo en su sentido negativo, que en la primera parte de la pieza se vinculaba con el descenso (de la pólis al inframundo, del corazón al bajo vientre) es ahora resemantizado en clave literaria. Superar ese miedo irracional lleva aquí al temor positivo que permite -mediante una audacia prudente sustentada en el reconocimiento de la sabiduría- dar lo mejor de cada uno en el combate. El público, sutil, sabrá comprender ese postulado, ya sugerido antes en vano por Dioniso cuando alegaba que, a diferencia de quienes son cobardes (que se quedaban recostados), él se levantó (v. 490). Ahora, las consecuencias son las opuestas. Frente a la inmovilidad a la que había sido sometida el dios, ahora el phóbos incentiva a la acción.

$\mathrm{Al}$ trasladarse (un nuevo movimiento, esta vez metafórico) del plano bélico al plano dramático, el concepto de temor también cobra nuevos alcances. Esto explica que, habiendo instado a dejar de lado el phóbos, el propio coro tenga miedo, de modo explícito, de las críticas que se le puedan hacer al mejor de los contrincantes: "temo

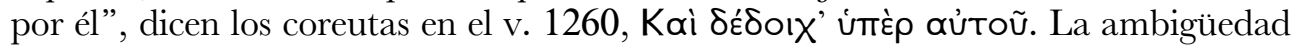
de la referencia del pronombre es significativa en nuestra lectura y puede referirse a cualquiera de los dos tragediógrafos ${ }^{33}$. Frente a esta incertidumbre, nuestra interpretación recupera el valor de la ambigüedad porque el temor está presente y se justifica -en términos políticos- respecto de cualquier poeta que el pueblo sea incapaz de valorar en su sabiduría. Recordemos tres versos del epírrhema, en el que ya se había mencionado la necesidad de eliminar los temores (vv. 686-688):

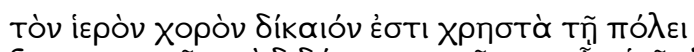

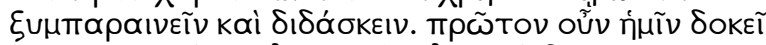

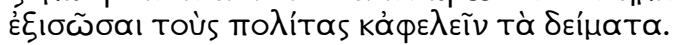

Es justo que el coro sagrado exhorte y enseñe a la ciudad cosas útiles. Ciertamente nos parece bien primero igualar a los ciudadanos y apartar los temores.

Si la parábasis tiene por objeto crear mensajes directos para el público teatral, aquí la consigna -literaria en su concepción- tiene fuertes alcances políticos ${ }^{34}$ : el rechazo de

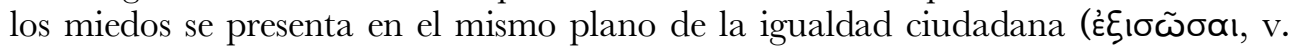
688). El coro, en esta instancia, manipula el vocabulario del temor para identificar los condicionamientos positivos del coraje y la negatividad inherente de la cobardía en la

33 Sommerstein 1996, 269, en su edición ha supuesto que se trata de Eurípides; Dover 1993, 344, en cambio, estima que se trata de Esquilo.

${ }_{34}$ No hay duda de la importancia extra-dramática de este posicionamiento jurídico aunque, como señala ARNOTT (1991), en términos históricos las propuestas concretas presentadas luego (el perdón a quienes se hubieran exiliado después del golpe oligárquico del 411-410 a.C. y la conformación de un gobierno democrático a cargo de las familias más nobles) hayan resultado luego un fracaso. 
determinación de la nueva realidad cívica que la comedia postula como propósito didáctico para el mejoramiento de la vida en la pólis.

Un pasaje de los Memorabilia de Jenofonte sea quizás ilustrativo para mostrar, comparativamente, los alcances vagos del miedo en cuanto a sus efectos, tanto en el plano del combate militar cuanto sobre el escenario teatral. Se trata del pasaje III 5, 5-6, en el que se reproducen unas palabras dirigidas por Sócrates al hijo de Pericles:

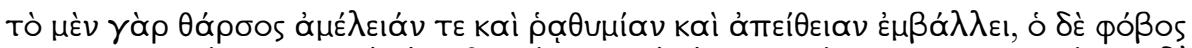

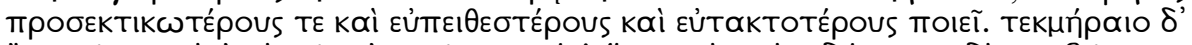

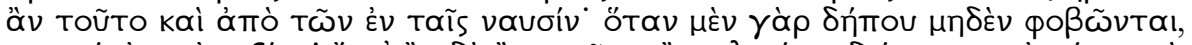

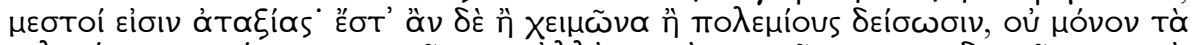

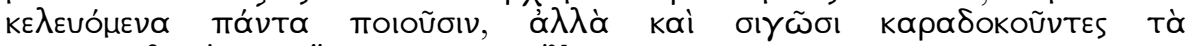

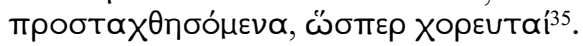

Pues el atrevimiento (thársos), por un lado, arroja despreocupación, negligencia y desobediencia, mientras que el miedo (phóbos) nos hace más atentos, más obedientes y más ordenados. Se podría probar esto a partir de las cosas vinculadas con los barcos: pues cada vez que los marineros no temen a nada, están llenos de desorden; pero cuando temen una tormenta o a los enemigos, no sólo hacen las cosas que se les ordena, sino que además se callan esperando instrucciones, como los miembros de un coro.

El pasaje de Jenofonte recupera la puesta en contacto de los planos militar y dramático. La buena organización y el respeto de las indicaciones que, según Sócrates, se desprenden del temor se contraponen con la anarquía que genera la osadía, pues implican actuar de modo racional bajo las ordenes impuestas por la autoridad naval -en el caso de los marineros- o por el dramaturgo, cuando se trata de los coreutas. En esta operación se equipara la buena administración de una embarcación con el correcto entrenamiento de quienes participan en una puesta en escena. Con todo ello, y volviendo a Ranas, parece propicio reconocer la antítesis que se genera entre el descenso -que genera la despreocupación- y el ascenso que, al final de la pieza, experimentará Esquilo, el buen poeta, quien dice cosas útiles para la pólis (vv. 15281532):

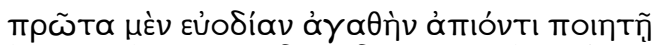

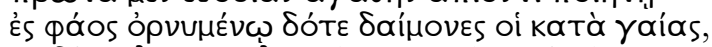

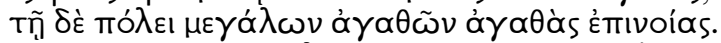

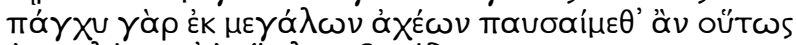

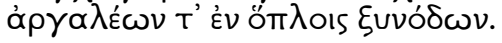

Primero otorgad, por un lado, un buen viaje al poeta que sube a la luz, vosotras divinidades de bajo tierra, y [otorgad] por el otro a la ciudad buenos proyectos de grandes bienes. Pues así podríamos detener por completo las grandes aflicciones y las dolorosas confrontaciones armadas.

\footnotetext{
${ }^{35} \mathrm{El}$ texto griego corresponde a la edición de MARCHANT 1971².
} 
La identificación del mejor tragediógrafo implica el movimiento contrario del que produce el terror paralizante que había detenido a Dioniso, porque activa un deslizamiento virtuoso superador de la disputa militar que genera sufrimiento y que degrada el tejido social. Por lo demás, del phóbos identificado con el plano meramente individual y corporal a un phóbos colectivo destinado a movilizar a los ciudadanos, la comedia explota la polivalencia de una emoción muy adecuada a las configuraciones imaginativas que la escena permite ${ }^{36}$. De hecho, el propio Esquilo -quien ganará el certamen literario- sostiene que su obra promovía el coraje entre los ciudadanos (vv. 1039-1042) ${ }^{37}$.

$\mathrm{El}$ ascenso que la obra consagra en su clausura se produce desde el Hades a Atenas, pero también desde el pánico que inmoviliza al temor que engendra coraje. Este dispositivo de acción permitirá dejar de lado los conflictos intestinos, en la doble acepción que la obra parece consagrar a este adjetivo: tanto los sufrimientos estomacales experimentados por Dioniso como las contiendas civiles que habían atravesado los ciudadanos de la Atenas de la época.

La contradicción del discurso y los hechos que había llevado a Dioniso a su inacción abre ahora las puertas a la valentía del dramaturgo (de Esquilo pero también del propio Aristófanes) que supera con palabras el temor a lo desconocido y, como un buen guerrero, se moviliza frente a ese miedo -y se alimenta de él- para defender los mejores planes y consagrar el mejor repertorio afectivo para una ciudad en crisis ${ }^{38}$.

\section{Conclusiones}

En el libro que mencionamos a comienzos de este trabajo, Martha Nussbaum describe el individualismo antidemocrático del miedo, pero al mismo tiempo ofrece la esperanza como su contrapartida. Tomando el ejemplo de Martin Luther King, la filósofa muestra cómo la esperanza, que al igual que el miedo se funda en la impotencia frente a lo que sobreviene, empuja no hacia la huida sino hacia el trabajo constructivo. Traducir el temor en una emoción más positiva, que permita alimentar la buena ciudadanía mediante una contención de las amenazas, es en su opinión el paso hacia un mejor régimen democrático ${ }^{39}$.

Sobre esta interpretación, es factible afirmar respecto de Ranas que, si en la primera parte de la comedia se opone, en un personaje como Dioniso, el coraje pretendido y el temor real para mostrar los efectos de un descenso real y uno figurado, en los versos corales de la segunda parte se consagra una arenga que, en términos de

36 También la tragedia, de hecho, escenifica lo político a partir del temor que produce el "otro", lo que SAXONHOUSE 1992, 22, ha llamado «fear of diversity».

37 BALOT 2014, 248.

${ }^{38}$ De hecho, sabemos que Aristófanes ganó el primer premio en las Leneas de su año, y los escoliastas antiguos reconocieron que ello se había debido a su alegato a favor de la reconciliación en la parábasis (según su Vita [K-At] test. 1, 35-39), lo que llevó a que se le concediera la posibilidad excepcional de una segunda representación de la obra (Dicearco, fr. 84 Wehrli).

39 Acerca de la posibilidad de ver el temor en la antigüedad como una emoción positiva en el escenario político, véase KAPUST 2008. 
combate, responde a una lógica performativa bélica que procura imponer orden, canalizar los sentimientos y elevar las virtudes positivas de quien inicia un enfrentamiento para brindar soluciones más efectivas. A partir de las metáforas bélicas el coro abraza la esperanza, aconsejando a los poetas que concursan para que rehúyan del temor que produce la ignorancia del público y asuman el desafío de luchar por un fin mejor.

Dioniso representa las ambivalencias de este movimiento y es el factor que unifica la comedia sobre la base de estas experiencias emotivas. Su inacción se supera cuando termina eligiendo, con criterios éticos, a Esquilo como el mejor autor de tragedias (v. 1471), puesto que se trata de quien mejor aconsejaría a la pólis (vv. 1420-1421) ${ }^{40}$. Del miedo paralizante el personaje avanza hacia un compromiso activo con la ciudadanía; del interés individual Dioniso se desplaza hacia la protección del bienestar común, en un último movimiento de ascenso que se contrapone a la katábasis que despliega la trama ${ }^{41}$.

En la personalidad del dios del descontrol, que es también del teatro, la comedia personifica en múltiples niveles los vaivenes y deslizamientos que el coro refiere al aconsejar, como programa político-literario, la valentía de quien confía en un lógos destinado a mejorar la vida en la pólisi ${ }^{42}$. En Ranas, pues, se encuentran interesantes líneas de continuidad si tenemos en cuenta los vínculos que en la primera parte de la pieza se entablan entre el pánico y la cobardía y que en la segunda parte se resuelven en los dos teatros de operaciones que suponen la batalla y el escenario. Frente al miedo privado y apolítico que produce risa al privar a quien lo vive de su condición ciudadana se consagra un phóbos político que moviliza e instruye.

La comedia encuentra, pues, una unidad estructurante sustentada en un guión emotivo eficaz. A fin de cuentas, se trata de cerrar la obra con el reconocimiento de aquel coraje que, a causa del temor mismo, despliega un guerrero valiente en el conflicto, que no es ni más ni menos que una manifestación otra del mismo coraje que, en el certamen dramático, el poeta sabio ha de traducir en la producción teatral para educar afectivamente a su auditorio ${ }^{43}$.

\footnotetext{
${ }^{40}$ En una contribución reciente sobre la impronta política de Ranas, BALDWIN 2014, 184, parte de la premisa de que la obra transforma a Dioniso, que pasa de ser exclusivamente el dios del teatro a ser un dios de la ciudad. Ese pasaje, en nuestra opinión, se explica también por la consagración de bases diferentes del temor y por el juego con sus alcances emotivos: desde el miedo propio de un protagonista cómico se pasa a la confianza en un phóbos cívico de fuertes alcances políticos.

${ }^{41} \mathrm{Si}$ siguiéramos las reflexiones ya planteadas por RiвOT 1925, 217, desde la psicología, podríamos pensar que la primera parte de la obra plantea un temor primitivo, instintivo, inconsciente, mientras que la segunda parte se focalizaría más bien en un temor secundario, consciente, razonado y posterior a la experiencia. En realidad, preferimos considerar que ambas modalidades del temor no son distinguibles sino que integran una única experiencia emotiva compleja.

42 Precisamente, con el resultado del certamen Dioniso (el patrón de los festivales cívicos atenienses) termina corporizando el nexo complejo de interrelación entre el autor literario y el cuerpo de ciudadanosespectadores, como afirma LADA-RICHARDS 1999, 223.

43 Afirman Slutter-Rosen 2003, 18: «If the parabases of Wasps and Peace, with their foregrounding of fearlessness and bravery and their invocation of Heracles were all we had, we could still comfortably maintain that Aristophanes (and indeed all comic poets engaged in satire and mockery)
} 


\section{Bibliografía}

- Bibliografía primaria

Dover, K. (1993) (ed.), Aristophanes, Frogs, Oxford.

Frenkel, D. et al. (2011), (eds.) Aristófanes, Ranas, Buenos Aires.

Henderson, J. (2002) (ed.), Aristophanes, Frogs, Assemblywomen, Wealth, Cambridge (MA)London.

Marchant, E.C. (19712) (ed.), Xenophontis opera omnia, II, Oxford (1921).

Rogers, B.B. (1968) (ed.), Aristophanes, II (The Peace, The Birds, The Frogs), Cambridge (MA)-London.

Ross, W.D. (1959) (ed.), Aristotle, Ars Rhetorica, Oxford.

Sommerstein, A.H. (1996) (ed.), Aristophanes, Frogs, Warminster.

- Bibliografía crítica e instrumenta studiorum

Arnott, W.G. (1991), «A Lesson from the 'Frogs'», Greece and Rome 38 (1), 18-23.

Baldwin, Ch. (2014), «Learning the Lesson of Dionysus: Aristophanes' Tragicomic Wisdom and Poetic Politics in the Frogs», en Mhire, J.J.-B.-P. Frost (eds.), The Political Theory of Aristophanes. Explorations in Poetic Wisdom, New York, 183-199.

Balot, R.K. (2014), Courage in the Democratic Polis. Ideology and Critique in Classical Athens, Oxford.

Bassi, K. (2003), «The Semantics of Manliness in Ancient Greece», en Sluiter, I. - Rosen, M.R. (eds.), Andreia: studies in manliness and courage in classical antiquity, LeidenBoston, 25-58.

Bisquerra, R. (2017), Política y emoción. Aplicaciones de las emociones a la política, Madrid.

Bliquez, L. (2008), «The purrikhē of Kinesias, a Pun?: Aristophanes Frogs 153», Classical Quarterly 58, 1, 320-326.

Bonanno, D. - Corso, L. (2018), «What Does Nemesis Have to Do with the Legal System? Discussing Aristotle's Neglected Emotion and Its Relevance for Law and Politics», en Huppes-Cluysenaer, L. - Coelho, N.M.M.S. (eds.), Aristotle on Emotions in Law and Politics, Cham, 237-259.

Buis, E.J. (2008), «Les (en)jeux d'un 'affranchissement' dramatique: la subjectivité légale de Xanthias dans les Grenouilles d'Aristophane», en Gonzales, A. (ed.), La fin du statut servil ? (Affranchissement, libération, abolition...) Hommage à Jacques Annequin [XXX Colloque du GIREA], II, Besançon, 419-435.

Buis, E.J. (2018), Taming Ares. War, Interstate Law and Humanitarian Discourse in Classical Greece [Series on Studies in the History of International Law, 26], Leiden-Boston.

claim a form of andreia for their poetic enterprises, even if other terminology and metaphors are used to convey it. Such is the imaginary environment they have constructed through their rhetoric, a battlefield in which the comic poet willingly and knowingly confronts equally self-construed dangers». 


\section{EMILIANO Buis}

Buis, E.J. (2020), «Helena o Palamedes, encomio o apología: la administración de flujos afectivos como estrategia judicial en los alegatos gorgianos», en Chialva, I. - Correa, J. -

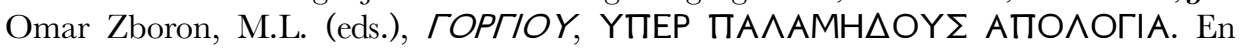
Defensa de Palamedes de Gorgias, Buenos Aires, 193-235 [en prensa].

Chantraine, P. (1999 [1968]), Dictionnaire étymologique de la langue grecque. Histoire des mots, Paris.

Csapo, E. (2010), «The Production and Performance of Comedy in Antiquity», en Dobrov, G.W. (ed.), Brill's Companion to the Study of Greek Comedy, Leiden-Boston, 103-142.

Davies, W.A. (1987), «The Varieties of Fear», Philosophical Studies 51, 287-310.

de Courville Nicol, V. (2011), Social Economies of Fear and Desire. Emotional Regulation, Emotion Management, and Embodied Autonomy, New York.

Delumeau, J. (2002), «Miedos de ayer y de hoy», en Villa Martínez, M.I. (ed.), El miedo. Reflexiones sobre su dimension social y cultural, Medellín, 9-21.

Demont, P. (1997), «La peur et le rire: la perception de l'esclavage dans les Grenouilles d'Aristophane», en Serghidou, A. (ed.), Fear of Slaves - Fear of Enslavement in the Ancient Mediterranean (Discourse, representations, practices) [XXIX Colloque du GIREA, Rethymnon 4-7 november 2004], Besançon, 179-192.

Fortenbaugh, W.W. (20022), Aristotle on Emotion, London.

Fuselli, S. (2018), «Logoi enuloi. Aristotle's Contribution to the Contemporary Debate on Emotions and Decision-Making», en Huppes-Cluysenaer, L. - Coelho, N.M.M.S. (eds.), Aristotle on Emotions in Law and Politics, Cham, 91-111.

Gray, J.A. (1987 [1971]), The Psychology of Fear and Stress, New York.

Hâncu, M.-G. (2016), «Фóßos and its place in Hesiod's Theogony», en Dumitru Oancea, M.L. - Halichias, A.-C. - Popa, N.-A. (eds.), Expressions of Fear from Antiquity to the Contemporary World, Cambridge, 11-18.

Heller, A. (1990), Una teoría de los sentimientos, México (edición original: Assen 1979).

Hollander, J. (2004), «Fear itself», Social Research 71, 4, 865-886.

Kapust, D.J. (2008), «On the Ancient Uses of Political Fear and Its Modern Implications», Journal of the History of Ideas 69, 353-373.

Kidd, S.E. (2014), Nonsense and Meaning in Ancient Greek Comedy, Cambridge.

Konstan, D. (2006), The Emotions of the Ancient Greeks. Studies in Aristotle and Classical Literature, Toronto-Buffalo-London.

Konstan, D. (2008), A life worthy of the gods: The materialist psychology of Epicurus, Las Vegas.

Kristjánsson, K. (2007), Aristotle, Emotions, and Education, Aldershot.

LaCourse Munteanu, D. (2012), Tragic Pathos. Pity and Fear in Greek Philosophy and Tragedy, Cambridge.

Lada-Richards, I. (1999), Initiating Dionysus. Ritual and Theatre in Aristophanes' Frogs, Oxford.

Marks, I. (1987), Fears, Fobias and Rituals, New York.

Nagy, G. (2010), «The Subjectivity of Fear as Reflected in Ancient Greek Wording», Dialogues 5, 29-45. 
Nussbaum, M.G. (2018), The Monarchy of Fear. A Philosopher Looks at our Political Crisis, New York.

Ribot, Th. (1925), La psychologie des sentiments, Paris.

Russo, C.F. (1994), Aristophanes. An Author for the Stage, London-New York (edición original: Firenze 1962).

Saxonhouse, A.W. (1992), Fear of Diversity. The Birth of Political Science in Ancient Greek Thought, Chicago.

Sluiter, I. - Rosen, R.M. (2003), «General Introduction», en Sluiter, I. - Rosen, R.M. (eds.), Andreia: studies in manliness and courage in classical antiquity, Leiden-Boston, 1-24.

Starkstein, S. (2018), A Conceptual and Therapeutic Analysis of Fear, Cham.

Tappolet, C. (2010), «Emotion, Motivation, and Action: The Case of Fear», en Goldie, P. (ed.), The Oxford Handbook of Philosophy of Emotion, Oxford, 325-345.

Whitman, C.H. (1964), Aristophanes and the Comic Hero, Cambridge (MA).

Zaborowski, R. (2002), La crainte el le courage dans l' Iliade et I'Odysée, Varsovie. 